\title{
Early outcomes of laparoscopic total gastrectomy with hemi-double stapling technique in gastric cancer
}

\author{
Servet Karagül,' ${ }^{10}$ Oktay Karaköse ${ }^{2}$ \\ 'Department of Gastroenterological Surgery, Samsun Training and Research Hospital, Samsun, Turkey \\ 2Department of Surgical Oncology, Samsun Training and Research Hospital, Samsun, Turkey
}

\begin{abstract}
Introduction: The most difficult step of laparoscopic total gastrectomy for gastric cancer is esophagojejunostomy anastomosis. Although various techniques are recommended for this anastomosis, there is no standard method. This study aims to present the outcomes of our patients who underwent esophagojejunostomy using the hemi-double stapling technique (HDST).

Materials and Methods: Patients who had laparoscopic surgery due to gastric cancer in our hospital between October 2016 and May 2019 were retrospectively analyzed. Patients who underwent laparoscopic total gastrectomy with HDST were included in this study. The patients' clinical characteristics and histopathological data were evaluated. Age, sex, body mass index (BMI), comorbidities, and American Society of Anesthesiologists (ASA) scores were documented. Operative time, intraoperative blood loss, specimen extraction site, day of oral intake, length of stay, postoperative complications, and mortality were evaluated.

Results: A total of 13 patients (eight male, five female) were included in this study. The mean age was $63.3 \pm 15.8$ years, and mean BMI was $26.4 \pm 6.8 \mathrm{~kg} / \mathrm{m}^{2}$. ASA score was ASA III in seven patients (54\%), ASA II in three patients (23\%), and ASA I in the remaining three patients (23\%). Mean operative time was $222.7 \pm 39.6$ minutes, and mean intraoperative blood loss was $97.3 \pm 52.4 \mathrm{~mL}$. There were no complications related to esophagojejunostomy. A mean of $23.8 \pm 11.1$ lymph nodes was removed, of which a mean of $10.8 \pm 11.9$ were tumor-positive. Mean length of stay was 10.9 \pm 9.8 days, and mean follow-up was $10.1 \pm 7$ months.
\end{abstract}

Conclusion: HDST appears to be a safe method that can be used in the esophagojejunostomy step of laparoscopic total gastrectomy for gastric cancer.

Keywords: Esophagojejunostomy; gastric cancer; laparoscopy; total gastrectomy.

\section{Introduction}

Gastric cancers are the fifth common malignancy and the third leading cause of cancer-related deaths worldwide.

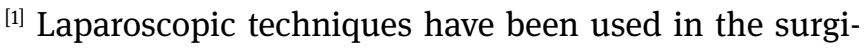
cal treatment of gastric cancer for approximately 25 years. ${ }^{[2]}$ Laparoscopic gastrectomies have been found to be on- cologically safe and result in acceptable survival rates as open gastrectomy, and two approaches are comparable in terms of morbidity and mortality. ${ }^{[3,4]}$ While laparoscopic distal gastrectomy has gained popularity over the years, laparoscopic total gastrectomy (LTG) has not become 
as common. ${ }^{[5]}$ This is due to the technical difficulty of esophagojejunostomy (EJS) anastomosis in LTG.

EJS anastomoses can be done in various ways, and no method has been adopted as a standard technique. Surgeons have conducted studies on various EJS techniques using linear or circular staplers in LTG. However, there is still insufficient data to support the superiority of one technique over the other. ${ }^{[6-8]}$ Important factors to consider include not only reliability and safety in terms of complications, but also how feasible the method is to perform during laparoscopy. Using purse-string sutures while placing the anvil of the circular stapler is one of the most challenging steps of LTG due to difficulties in terms of field of view and maneuverability. Using the HDST for EJS anastomosis has been presented as an easy and reliable method. ${ }^{[9,10]}$ Our aim in the present study was to evaluate the applicability of the HDST by sharing our outcomes of LTG using this method.

\section{Materials and Methods}

Patients who had laparoscopic surgery due to gastric tumor in our hospital between October 2016 and May 2019 were retrospectively analyzed. Gastric cancer patients who underwent LTG with HDST were included in the study. Patients who had subtotal gastrectomy or laparoscopic surgery for reasons other than cancer were excluded from the study. Ethical approval was obtained from the Samsun Training and Research Hospital Ethics Committee (Number: 2019/14). All patients provided written informed consent. The patients' clinical characteristics and histopathological data were evaluated. Their age, sex, body mass index (BMI), comorbidities, and American Society of Anesthesiologists (ASA) scores were documented. Operative time, intraoperative blood loss, specimen extraction site, day of oral intake, length of stay, postoperative complications, and mortality were evaluated.

All data were recorded in a Microsoft Excel file. Categorical data of the patients are presented as mean \pm standard deviation. Continuous variables are expressed as number and percentage.

\section{Surgical Technique}

Under general anesthesia, the patients were placed in $30^{\circ}$ reverse Trendelenburg position with legs apart. Following abdominal insufflation via Veress needle entry through the umbilicus, a 10-mm trocar was placed and a camera was introduced through this port. We placed 12-mm and 5-mm in the upper right quadrant and 10-mm and 5-mm trocars in the upper left quadrant. A Nathanson retractor was used to elevate the liver. Gastrocolic ligament was cut along with the upper margin of transverse colon. Greater omentum was completely freed, and the bursa omentalis was opened. Right gastric artery and right gastroepiploic artery were ligated with clips. Duodenum was transected using a laparoscopic stapler. Following dissection of the anterosuperior lymph nodes along the hepatic artery and proximal and distal lymph nodes along the splenic artery, left gastric artery and vein were ligated with clips. Esophagocardiac junction was mobilized by dissection, while the relevant regional lymph nodes were excised with the specimen.

Before transecting the esophagus, the first step of HDST was performed. First, we knotted approximately $8 \mathrm{~cm}$ of polypropylene suture with needle to the end of the anvil of a 25-mm circular stapler (Fig. 1a). We pulled the stomach caudally and performed an esophagotomy (Fig. 1b). The anvil was inserted into the esophagus through this incision and advanced toward the proximal esophagus (Fig. 1c). The needle of the suture on the anvil tip was passed through the anterior wall of the esophagus (Fig. 1d). When the suture was taut, we transected the esophagus immediately distal to it using a laparoscopic linear stapler (Fig. 1e). The anvil suture was cut and removed, and Roux-en-Y reconstruction was initiated. We enlarged the $10-\mathrm{mm}$ trocar incision on the left to allow insertion of the circular stapler and the EJS was completed. Jejunojejunostomy was performed with the laparoscopic linear stapler. The stapler orifice was closed intracorporeally using $3 / 0$ polypropylene suture. We extracted the specimen from the abdomen either through the enlarged trocar incision on the left or via the suprapubic or transvaginal route.

\section{Results}

A total of 13 patients, 8 men and 5 women, were included in the study. Their mean age was $63.3 \pm 15.8$ years and mean BMI was $26.4 \pm 6.8 \mathrm{~kg} / \mathrm{m}^{2}$. Comorbidities included hypertension (HT) in 5 patients, diabetes mellitus (DM) in 3 patients, chronic obstructive pulmonary disease (COPD) in 3 patients, coronary artery disease (CAD) in 2 patients, and abdominal aortic aneurysm, iron deficiency anemia, and hypothyroidism in 1 patient each. ASA score was ASA II in 7 patients (54\%), ASA II in 3 patients (23\%), and ASA I in the remaining 3 patients (23\%) (Table 1$)$. 

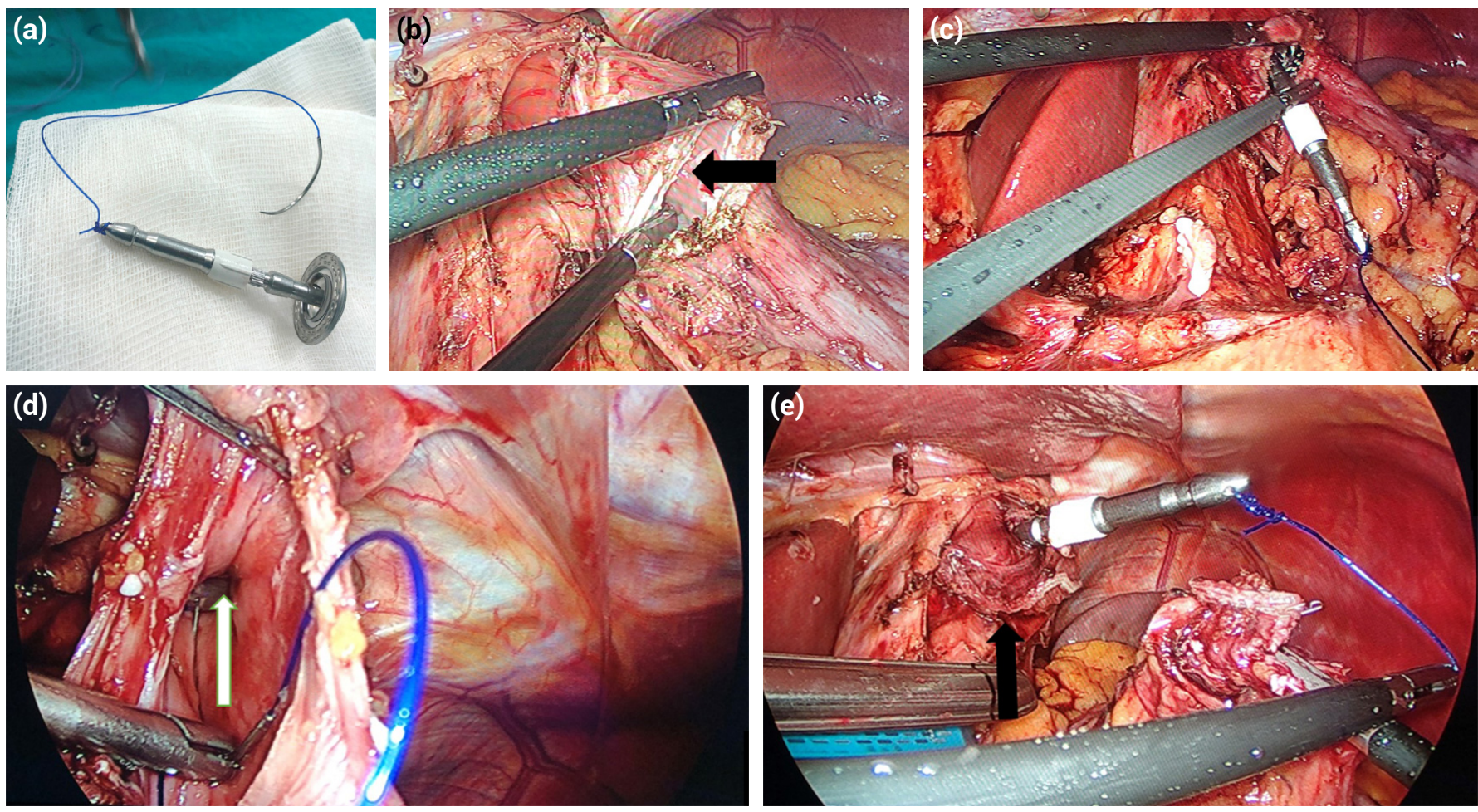

Figure 1. (a) Anvil with polypropylene suture. (b) Esophagotomy (Black arrow shows the anterior wall of esophagus with esophagotomy). (c) Anvil placement into the esophagus. (d) Suture pass through the anterior esophageal wall (White arrow shows entrance point for needle). (e) Transection of esophagus (Black arrow shows the esophageal stump with anvil).

The mean operative time was $222.7 \pm 39.6$ minutes and mean intraoperative blood loss was $97.3 \pm 52.4 \mathrm{~mL}$. Specimen removal was performed by enlarging the trocar incision in
10 cases, while a suprapubic incision was made in 2 cases. Natural orifice specimen extraction (NOSE) via transvaginal route was used in 1 case. The mean time to oral intake

Table 1. Features of the patients

\begin{tabular}{|c|c|c|c|c|c|}
\hline $\begin{array}{l}\text { Patients } \\
(n=13)\end{array}$ & $\begin{array}{c}\text { Age } \\
\text { (year) }\end{array}$ & Gender & $\begin{array}{c}\text { BMI } \\
\left(\mathrm{kg} / \mathrm{m}^{2}\right)\end{array}$ & Co-morbidity & ASA \\
\hline 1 & 53 & Male & 24.2 & Iron deficiency anemia & 2 \\
\hline 2 & 60 & Female & 32 & DM, HT, COPD, hypothyroidism & 3 \\
\hline 3 & 65 & Female & 40.3 & $\mathrm{DM}, \mathrm{HT}, \mathrm{CAD}$ & 3 \\
\hline 4 & 44 & Male & 19.2 & None & 2 \\
\hline 5 & 79 & Male & 20.7 & HT & 3 \\
\hline 6 & 79 & Female & 19.5 & HT & 2 \\
\hline 7 & 84 & Male & 17.5 & None & 3 \\
\hline 8 & 41 & Male & 28.2 & None & 1 \\
\hline 9 & 46 & Female & 27 & None & 1 \\
\hline 10 & 77 & Male & 24.9 & $\begin{array}{c}\text { HT, DM, CAD, COPD, } \\
\text { abdominal aortic aneurysm }\end{array}$ & 3 \\
\hline 11 & 81 & Female & 33 & COPD & 3 \\
\hline 12 & 46 & Male & 33.9 & None & 1 \\
\hline 13 & 68 & Male & 23.3 & None & 3 \\
\hline
\end{tabular}

ASA: American Society of Anesthesiologists scores. BMI: Body mass index; DM: Diabetes mellitus; HT: Hypertension; COPD: Chronic obstructive pulmonary disease; CAD: Coronary artery disease. 
Table 2. Outcomes of the patients

\begin{tabular}{lccccccccc}
$\begin{array}{l}\text { Patients } \\
(\mathbf{n = 1 3})\end{array}$ & $\begin{array}{c}\text { Operative } \\
\text { time } \\
(\mathbf{m i n})\end{array}$ & $\begin{array}{c}\text { Blood } \\
\text { loss } \\
(\mathbf{m L})\end{array}$ & $\begin{array}{c}\text { Postop } \\
\text { morbidity }\end{array}$ & $\begin{array}{c}\text { Postop } \\
\text { mortality }\end{array}$ & $\begin{array}{c}\text { Diagnosis } \\
\text { Dissected } \\
\text { LN }\end{array}$ & $\begin{array}{c}\text { Positive } \\
\text { LN }\end{array}$ & $\begin{array}{c}\text { Hospital } \\
\text { stay } \\
\text { (day) }\end{array}$ & $\begin{array}{c}\text { Follow-up } \\
\text { (month) }\end{array}$ \\
\hline 1 & 170 & 80 & - & - & Adeno Ca & 41 & 19 & 8 & 8 \\
2 & 240 & 100 & - & - & Adeno Ca & 18 & 0 & 8 & 9 \\
3 & 230 & 50 & - & - & Adeno Ca & 26 & 14 & 7 & 15 \\
4 & 250 & 70 & Paralytic ileus & - & Adeno Ca & 13 & 10 & 18 & 9 \\
5 & 190 & 40 & - & - & Adeno Ca & 16 & 9 & 6 & 13 \\
6 & 210 & 80 & - & - & Adeno Ca & 16 & 7 & 9 & 7 \\
7 & 160 & 20 & - & - & Adeno Ca & 15 & 1 & 7 & 10 \\
8 & 250 & 150 & - & - & Adeno Ca & 42 & 39 & 9 & 9 \\
9 & 240 & 100 & - & - & Adeno Ca & 22 & 2 & 7 & 23 \\
10 & 210 & 120 & - & - & Adeno Ca & 32 & 29 & 8 & 23 \\
11 & 250 & 80 & Pneumonia, & - & Adeno Ca & 17 & 6 & 42 & 1.4 \\
& & & ARDS & & & & & & 2 \\
12 & 305 & 175 & -- & -- & Adeno Ca & 12 & 4 & 6 & 2 \\
13 & 190 & 200 & -- & -- & Adeno Ca & 39 & 0 & 7 & 2 \\
\hline
\end{tabular}

LN: Lymph node; ARDS: Acute respiratory distress syndrome.

was $3.7 \pm 0.9$ days. In terms of postoperative complications, one patient had paralytic ileus which was managed with medical treatment. One patient had postoperative acute respiratory distress syndrome (ARDS). This patient did not respond to treatment and died on postoperative day 42. A mean of $23.8 \pm 11.1$ lymph nodes were removed, of which a mean of $10.8 \pm 11.9$ were tumor-positive. The mean length of stay was $10.9 \pm 9.8$ days, and the mean duration of follow-up was $10.1 \pm 7$ months.

\section{Discussion}

As with surgery for other oncologic diseases, various studies in the literature have investigated whether appropriate treatment is applied in the laparoscopic treatment of gastric cancer, and research on this topic is still ongoing. Currently available data indicate that in addition to the advantages of minimally invasive surgery, such as rapid recovery, reduced blood loss, less pain, and fewer surgical site complications, laparoscopic gastric cancer surgery also provides acceptable oncological outcomes. ${ }^{[1-}$ ${ }^{16]}$ In our clinic, we try to utilize laparoscopic approaches in gastroenterologic cancer surgery as much as possible.

One of the main goals in the treatment of gastric cancer is to perform adequate and appropriate lymph node dissection. ${ }^{[17,18]}$ In our clinic, we routinely perform D2 lymph node dissection in patients with indication for laparo- scopic surgical treatment of gastric cancer. We prefer to perform D1+ lymph node dissection only in T1NO cases. We do not perform prophylactic splenectomy unless there is lymph node metastasis close to the spleen or direct invasion of the spleen or distal pancreas. However, in these situations, we prefer open procedures rather than laparoscopic surgery. The gastric cancer patients who underwent LTG in this study had a mean of $23.8 \pm 11.1$ lymph nodes removed, which is acceptable.

The most difficult step in minimally invasive total gastrectomy is EJS anastomosis. There are various types of anastomosis and they can be made manually or using a stapler. Techniques using staplers can be classified as circular stapler and linear stapler techniques. ${ }^{[5]}$ Circular stapler techniques can be subcategorized as the single-stapling technique (SST), double-stapling technique (DST), and hemi-double-stapling technique. Linear stapler techniques can be subdivided into two groups, the functional end-to-end anastomosis (FEEA) and side-to-side anastomosis (overlap method). ${ }^{[19-27]}$ Although all of these techniques can be applied safely, it is not possible based on the available data to reach a consensus on whether any is superior to the others. ${ }^{[5-7]}$

The circular stapler technique is actually the standard method for open total gastrectomy. However, the diffi- 
culty of applying purse-string sutures to the esophagus during anvil placement in laparoscopic surgery is one of the reasons alternative methods have been sought. ${ }^{[15,21]}$ The linear stapler technique may be difficult for inexperienced surgeons because it requires greater mobilization of the esophagus and suturing of the stapler entry site. However, advantages of this technique are that the linear stapler is more suitability for insertion through a trocar, and an experienced surgeon can perform the anastomosis more easily using a linear stapler than a circular stapler. This is supported by evidence in the literature that operative time in LTG performed with linear stapler is significantly shorter than for LTG performed with circular stapler. However, no significant differences in terms of early and late complications have been reported between the two methods. ${ }^{[28]}$ Trocar entry sites are not large enough to insert circular staplers, necessitating either an additional incision or enlargement of the trocar incision. The extent to which this offsets the benefits of minimally invasive surgery has not been determined. Decisions regarding anastomosis technique are usually made according to the experience and preference of the surgeon. Although there are numerous methods, there is no enough comparative prospective studies to reach a conclusion about EJS technique.

Transoral insertion of the anvil facilitated the use of circular staplers. ${ }^{[19]}$ However, while this method is beneficial in the anastomosis stage of the procedure, it is both costly and requires assistance from health personnel other than the surgeon to implement. We use the HDST, ${ }^{[24]}$ which is another method that makes this step easier. In this study, we aimed to evaluate the applicability of this technique by sharing our HDST outcomes.

There are different technical methods for performing HDST during esophagojejunostomy. As described by Omori,, ${ }^{[24]}$ we first passed a suture through the hole at the anvil tip and knotted it, leaving a suture length of about $8 \mathrm{~cm}$. We then performed semicircumferential esophagotomy. The anvil with suture was advanced through this opening into the esophagus. The needle of the anvil suture was passed through the anterior wall of the esophagus and by pulling this suture, the tip of the anvil appeared as a protrusion in the anterior esophagus wall. With a linear stapler, we transected the esophagus immediately below this protrusion. Then, using the suture, we removed the tip of the anvil through the anterior wall of the esophagus and positioned the anvil for anastomosis.
Omori et al. ${ }^{[24]}$ observed no complications in their study including 10 patients. Similarly, we detected no complications related to the anastomosis in our study. We also obtained outcomes that are comparable in terms of operative time and blood loss. While they used the ECS 25 Ethicon Endo-Surgery as a circular stapler, we used the EEA $25 \mathrm{~mm}$ Covidien circular stapler. Though the anvil structure differs in these two staplers, we could not find any studies comparing them in terms of HDST.

Some surgeons are using HDST in LTG, but each group makes small modifications to the technique. ${ }^{[9,23,28]}$ In general, the practice varies in terms of how the circular stapler anvil is placed in the esophagus. As minimally invasive surgery for gastric cancer becomes more widely adopted, more information on the technical details and postoperative outcomes will become available. In our study, HDST seems to be a feasible and reliable method for the EJS step of LTG for the treatment of gastric cancer. Prospective studies and larger patient groups are needed to establish a standard method for EJS anastomosis.

\section{Disclosures}

Ethichs Committee Approval: The study was approved by the Local Ethics Committee.

Peer-review: Externally peer-reviewed.

Conflict of Interest: None declared.

\section{References}

1. Torre LA, Bray F, Siegel RL, Ferlay J, Lortet-Tieulent J, Jemal A. Global cancer statistics, 2012. CA Cancer J Clin 2015;65:87-108. [CrossRef]

2. Kitano S, Iso Y, Moriyama M, Sugimachi K. Laparoscopy-assisted Billroth I gastrectomy. Surg Laparosc Endosc 1994;4:146-8.

3. Lee JH, Lee CM, Son SY, Ahn SH, Park DJ, Kim HH. Laparoscopic versus open gastrectomy for gastric cancer: longterm oncologic results. Surgery 2014;155:154-64. [CrossRef]

4. Kim HH, Hyung WJ, Cho GS, Kim MC, Han SU, Kim W, et al. Morbidity and mortality of laparoscopic gastrectomy versus open gastrectomy for gastric cancer: an interim report-a phase III multicenter, prospective, randomized Trial (KLASS Trial). Ann Surg 2010;251:417-20. [CrossRef]

5. Kawaguchi $Y$, Shiraishi K, Akaike H, Ichikawa D. Current status of laparoscopic total gastrectomy. Ann Gastroenterol Surg 2018;3:14-23. [CrossRef]

6. Umemura A, Koeda K, Sasaki A, Fujiwara H, Kimura Y, Iwaya $\mathrm{T}$, et al. Totally laparoscopic total gastrectomy for gastric cancer: literature review and comparison of the procedure of esophagojejunostomy. Asian J Surg 2015;38:102-12. [CrossRef] 
7. Shim JH, Yoo HM, Oh SI, Nam MJ, Jeon HM, Park $\mathrm{CH}$, et al. Various types of intracorporeal esophagojejunostomy after laparoscopic total gastrectomy for gastric cancer. Gastric Cancer 2013;16:420-7. [CrossRef]

8. Sugiyama M, Oki E, Ogaki K, Morita M, Sakaguchi Y, Koga S, et al. Clinical Outcomes of Esophagojejunostomy in Totally Laparoscopic Total Gastrectomy: A Multicenter Study. Surg Laparosc Endosc Percutan Tech 2017;27:e87-e91. [CrossRef]

9. Ali B, Park $\mathrm{CH}$, Song KY. Intracorporeal esophagojejunostomy using hemi-double-stapling technique after laparoscopic total gastrectomy in gastric cancer patients. Ann Surg Treat Res 2017;92:30-4. [CrossRef]

10. Wang $H$, Hao Q, Wang $M$, Feng $M$, Wang $F$, Kang $X$, et al. Esophagojejunostomy after laparoscopic total gastrectomy by $\mathrm{OrVil}^{\mathrm{TM}}$ or hemi-double stapling technique. World J Gastroenterol 2015;21:8943-51. [CrossRef]

11. Chen QY, Zheng CH, Li P, Xie JW, Wang JB, Lin JX, et al. Which method is more suitable for advanced gastric cancer with enlarged lymph nodes, laparoscopic radical gastrectomy or open gastrectomy? Gastric Cancer 2018;21:853-63. [CrossRef]

12. Kim HH, Han SU, Kim MC, Hyung WJ, Kim W, Lee HJ, et al. Long-term results of laparoscopic gastrectomy for gastric cancer: a large-scale case-control and case-matched Korean multicenter study. J Clin Oncol 2014;32:627-33. [CrossRef]

13. Ahn SH, Kang SH, Lee Y, Min SH, Park YS, Park DJ, et al. Long-term Survival Outcomes of Laparoscopic Gastrectomy for Advanced Gastric Cancer: Five-year Results of a Phase II Prospective Clinical Trial. J Gastric Cancer 2019;19:102-10.

14. Li Z, Zhao Y, Lian B, Liu Y, Zhao Q. Long-term oncological outcomes in laparoscopic versus open gastrectomy for advanced gastric cancer: A meta-analysis of high-quality nonrandomized studies. Am J Surg 2019;218:631-8. [CrossRef]

15. Inokuchi M, Nakagawa M, Tanioka T, Okuno K, Gokita K, Kojima K. Long- and short-term outcomes of laparoscopic gastrectomy versus open gastrectomy in patients with clinically and pathological locally advanced gastric cancer: a propensity-score matching analysis. Surg Endosc 2018;32:735-42.

16. Kim SH, Chung Y, Kim YH, Choi SI. Oncologic Outcomes after Laparoscopic and Open Distal Gastrectomy for Advanced Gastric Cancer: Propensity Score Matching Analysis. J Gastric Cancer 2019;19:83-91. [CrossRef]

17. Lu C, Zhou S, Peng Z, Chen L. Quality of D2 lymphadenectomy for advanced gastric cancer: is laparoscopic-assisted distal gastrectomy as effective as open distal gastrectomy? Surg Endosc 2015;29:1537-44. [CrossRef]

18. Guideline Committee of the Korean Gastric Cancer Associ- ation (KGCA), Development Working Group \& Review Panel. Korean Practice Guideline for Gastric Cancer 2018: an Evidence-based, Multi-disciplinary Approach. J Gastric Cancer 2019;19:1-48. [CrossRef]

19. Ito $H$, Inoue $H$, Odaka $N$, Satodate $H$, Onimaru $M$, Ikeda $H$, et al. Evaluation of the safety and efficacy of esophagojejunostomy after totally laparoscopic total gastrectomy using a trans-orally inserted anvil: a single-center comparative study. Surg Endosc 2014;28:1929-35. [CrossRef]

20. Kinoshita T, Oshiro T, Ito K, Shibasaki H, Okazumi S, Katoh R. Intracorporeal circular-stapled esophagojejunostomy using hand-sewn purse-string suture after laparoscopic total gastrectomy. Surg Endosc 2010;24:2908-12. [CrossRef]

21. Jeong O, Park YK. Intracorporeal circular stapling esophagojejunostomy using the transorally inserted anvil (OrVil) after laparoscopic total gastrectomy. Surg Endosc 2009;23:2624-30.

22. Bracale U, Marzano E, Nastro P, Barone M, Cuccurullo D, Cutini G, et al. Side-to-side esophagojejunostomy during totally laparoscopic total gastrectomy for malignant disease: a multicenter study. Surg Endosc 2010;24:2475-9. [CrossRef]

23. Amisaki M, Kihara K, Endo K, Suzuki K, Nakamura S, Sawata $\mathrm{T}$, et al. Comparison of single-stapling and hemi-double-stapling methods for intracorporeal esophagojejunostomy using a circular stapler after totally laparoscopic total gastrectomy. Surg Endosc 2016;30:2994-3000. [CrossRef]

24. Omori T, Oyama T, Mizutani S, Tori M, Nakajima K, Akamatsu $\mathrm{H}$, et al. A simple and safe technique for esophagojejunostomy using the hemidouble stapling technique in laparoscopy-assisted total gastrectomy. Am J Surg 2009;197:e13-7. [CrossRef]

25. Okuno K, Gokita K, Tanioka T, Ogawa N, Otsuki S, Inokuchi M, et al. Esophagojejunostomy Using the Purse-String Suturing Device After Laparoscopic Total or Proximal Gastrectomy for Gastric Cancer. World J Surg 2017;41:2605-10. [CrossRef]

26. Yasukawa D, Hori T, Kadokawa Y, Kato S, Machimoto T, Hata $\mathrm{T}$, et al. Impact of stepwise introduction of esophagojejunostomy during laparoscopic total gastrectomy: a single-center experience in Japan. Ann Gastroenterol 2017;30:564-70.

27. Kang SH, Cho YS, Min SH, Park YS, Ahn SH, Park DJ, et al. Intracorporeal Esophagojejunostomy Using a Circular or a Linear Stapler in Totally Laparoscopic Total Gastrectomy: a Propensity-Matched Analysis. J Gastric Cancer 2019;19:193-201. [CrossRef]

28. Ichikawa D, Komatsu S, Kubota T, Okamoto K, Konishi H, Shiozaki A, et al. Evaluation of the safety and feasibility of laparoscopic total gastrectomy in clinical stage I gastric cancer patients. World J Surg 2015;39:1782-8. [CrossRef] 